(RESEARCH ARTICLE)

\title{
Neonatal care practiced by the mothers in Muslim-communities in Birgunj Metropolitan city, Parsa, Nepal
}

\author{
Panta Ganga 1, *, Neupane Sharmila ${ }^{2}$, Darshandhari Kapali Gayetri ${ }^{1}$, Koirala Manisa ${ }^{1}$ and Pant Ramesh ${ }^{3}$ \\ ${ }^{1}$ Maharajgunj Nursing Campus, Tribhuvan University Institute of Medicine, Kathmandu, Nepal. \\ ${ }^{2}$ Public Service Commission, Bagmati Province, Hetauda, Nepal. \\ ${ }^{3}$ Civil Service Hospital, Kathmandu, Nepal.
}

Publication history: Received on 18August 2020; revised on 11 September 2020; accepted on 15 September 2020

Article DOI: https://doi.org/10.30574/wjarr.2020.8.1.0311

\begin{abstract}
Neonatal period is the most vulnerable period of the survival of the child, so good neonatal care practices is crucial for the prevention of morbidity and mortality of a neonate. Descriptive cross-sectional study design with 219 Muslim women having less than 1year old babies were selected by probability sampling technique to find out the neonatal care practices. A semi-structured interview schedule was used for data collection. Data were analyzed using descriptive and inferential statistics. Early marriage and illiteracy is common in these Muslim communities. Only around half (49.8\%) of mothers had sufficient neonatal care practice. However, there is good eye care practice in those communities. All of the mothers practiced oil massage to their babies once or more than one time in a day. Regarding breastfeeding, more than four fifth (83.87\%) of mothers fed exclusively to their newborn; $13.24 \%$ mothers had home deliveries, among them $75.85 \%$ of deliveries were assisted by unskilled personnel. The significant association was found between level of neonatal care practice and age of mother ( $p$-value 0.024). Likewise, mother's education is also associated with the feeding of colostrum ( $p$-value 0.038). Insufficient neonatal care practiced was predominant among mothers of those Muslim communities so there is need for strengthening community awareness by mobilizing female community health volunteers (FCHVs). Home delivery by unskilled personnel is very common so they should be motivated for institutional delivery and completion of the recommended antenatal visits.
\end{abstract}

Keywords: Female Community Health Volunteers; Muslim Communities; Mothers; Neonate; Neonatal Care Practice

\section{Introduction}

Neonatal period is the most vulnerable period for the child's survival. Globally, nearly 6 million children are reported to have died, among them 45\% (2.7 million) during the neonatal period in 2015[1]. Almost one million neonatal deaths occurred on the day of birth and around two million died in the first week after the birth amongthem $43 \%$ die due to preventable infectious diseases such as pneumonia, diarrhea and sepsis [2]. Such situation mostly common in low and middle-income countries due to sub-standard neonatal care practice [3].Around 23,000 children die in Nepal each year before reaching their fifth birthday and three fifth babies die in their neonatal period [4].

Remarkable progress has been made in recent decades in the reduction of child deaths worldwide, but neonatal mortality rates have declined at a slower pace than expected [2]. Leading causes of neonatal deaths are pre-term birth, severe infections, asphyxia and low birth-weight. The rate of neonatal mortality is known to be dependent on various factors including maternal, child and birth related factors including socio-demographic characteristics of mothers and other caregivers' health care practices and treatment seeking behaviors [3].

\footnotetext{
* Corresponding author: Ganga Panta

Maharajgunj Nursing Campus, Tribhuvan University Institute of Medicine, Kathmandu, Nepal. 
Neonatal care include thermal protection, early and exclusive breast feeding, cleanliness, eye care, cord care, baby bath, immunization and care during illness, which are very crucial for the survival of neonate [1]. Despite the initiatives of the Government of Nepal, neonatal mortality has remained constant 33/1000 live births from 2006 to 2011 and reduced to $23 / 1000$ in 2014 , occupy $70 \%$ of total infant mortality rate of Nepal [5].Reducing newborn mortality at least $12 / 1000$ live birth is target of Sustainable Development Goals (SDG) in Nepal. Community Based Integrated Management of Childhood illness (CB-IMCI) and Community Based Neonatal Care Program (CB-NCP) was integrated into Community Based Integrated Management of Neonatal and Childhood Illness (CB-IMNCI) for effectiveness of the programme to reduce under five and neonatal morbidity and morbidity in 2015 [4].

Unhealthy neonatal care practices were found in rural Muslim community of Bangladesh; 6\% delivered by skilled providers, unclean cord care $42 \%$, and delay initiation of breastfeeding $60 \%$ and early bathing $71 \%$ [6]. Only one out of ten newborns in Nepal is found to have received optimum thermal care [7]. Majority of the women in urban Uganda had no knowledge of the importance of skin-to-skin care as a thermo protective measure [8].Initiation of breast feeding within one hour was found $52.5 \%$ at Tharu community of Chitwan [9], similarly, 36\% women in Nepal did not initiate breastfeeding within one hour of delivery $[10,7]$.

Neonatal mortality rate was 36/1000 live births among the babies born in disadvantaged caste and ethnic groups in Nepal compared with 26/1000 live births in non-disadvantage group [11].Despite various efforts laid by Government of Nepal to improve the mother and child condition, the success has remained far from expected. Therefore, the researchers felt an urgent need to study neonatal care practice especially those belonging minority and marginalized Muslim communities in Nepal.

\section{Methods}

Descriptive cross-sectional research study was used to carry out at Muslim communities of Birgunj Metropolitan city. Out of 32 wards of Birgunj Metropolitan City, 7 wards were selected where Muslim population densely resided. Two hundred nineteen women having less than 1year old babies were selected by probability simple random sampling technique with lottery method. Semi-structured interview schedule was developed by researchers themselves especially neonatal care practices focuses on eye \& cord care, thermal protection, breastfeeding and treatment seeking or utilization. Content validity was maintained through extensive literature review and consulting with the subject experts. Pretesting of the instrument was done among 10\% (22) respondents in similar setting in Bara district and some needed modification was done.

Ethical approval was taken from the Institution Review Board of Institute of Medicine. Subsequently, administrative approval obtained from Birgunj Metropolitan City office and ward secretaries of selected wards. Women were interviewed after obtaining, informed consent, which was taken from each respondent prior to data collection and participant's wish and refusal for participation respectfully allowed at any time of research. Researchers collected data at their door steps with face to face interview technique. After collecting data, it was reviewed, edited, organized, coded and entered in Epi-data and analyzed in SPSS. Descriptive statistics (percentage, frequency, mean and standard deviation) was use for neonatal care practice and inferential statistics (Chi-square test) was applied to measure the association and p-value was considered in $0.05 \%$ level of significance. 


\section{Findings}

Table1: Socio-demographic Characteristics of Respondents $(n=219)$

\begin{tabular}{|c|c|c|}
\hline Socio-demographic Characteristics & Frequency & Percent \\
\hline \multicolumn{3}{|l|}{ Age of the Mothers } \\
\hline$\leq 20$ years & 63 & 28.76 \\
\hline 20-29 years & 216 & 57.53 \\
\hline$\geq 30$ and above & 30 & 13.24 \\
\hline \multicolumn{3}{|l|}{ Education status of Mother } \\
\hline Cannot read and write & 73 & 33.33 \\
\hline Can only read and write & 24 & 10.95 \\
\hline Primary & 43 & 19.63 \\
\hline Secondary & 63 & 28.76 \\
\hline Higher Secondary and above & 16 & 7.30 \\
\hline \multicolumn{3}{|l|}{ Education status of Father } \\
\hline Cannot read and write & 33 & 15.06 \\
\hline Can only read and write & 17 & 7.76 \\
\hline Primary & 41 & 18.72 \\
\hline Secondary & 100 & 45.66 \\
\hline Higher Secondary and above & 28 & 12.78 \\
\hline \multicolumn{3}{|l|}{ Occupation of Mother } \\
\hline Homemaker & 217 & 99.08 \\
\hline Business/Labour & 2 & 0.9 \\
\hline \multicolumn{3}{|l|}{ Occupation of Father } \\
\hline Business & 73 & 33.33 \\
\hline Labourer/Rickshaw or Tanga puller/ Agriculture & 58 & 26.46 \\
\hline Service & 48 & 21.91 \\
\hline Foreign employment & 23 & 10.5 \\
\hline Driver & 17 & 7.76 \\
\hline \multicolumn{3}{|l|}{ Types of Family } \\
\hline Nuclear & 50 & 22.83 \\
\hline Joint & 130 & 59.36 \\
\hline Extended & 39 & 17.80 \\
\hline \multicolumn{3}{|l|}{ Economic Status } \\
\hline Insufficient for a year & 46 & 21.00 \\
\hline Sufficient for a year & 96 & 43.83 \\
\hline Sufficient for a year and surplus & 77 & 35.15 \\
\hline \multicolumn{3}{|l|}{ Birth Order } \\
\hline First child & 55 & 25.11 \\
\hline Second child & 70 & 31.96 \\
\hline Third child and more & 94 & 42.91 \\
\hline
\end{tabular}

Tables 1, shows that more than one quartered (28.7\%) of mothers were below 20 years. Mean \pm SD age of the mother was $23.94 \pm 4.39$, minimum 17 and maximum age was $40 \mathrm{yrs}$. There is pitiable condition of education status of mothers of newborn in those communities. Which revealed that, one third (33.33\%) of the mothers was illiterate in comparison 
to $15.06 \%$ father. Almost all $(99 \%)$ of the mothers were homemakers, however, all of the fathers were engaged in outside work for earning. More than half (59.36\%) were lived in joint family.

Table 2: Safe Delivery Practices of Respondents

\begin{tabular}{|l|l|l|}
\hline Characteristics & Frequency & Percent \\
\hline Planned for Hospital delivery (n 219) & 184 & 84.01 \\
\hline Place of Delivery (n 219) & & \\
\hline Hospital & 190 & 86.75 \\
\hline Home & 29 & 13.24 \\
\hline Assistant at Home Delivery (n 29) & & \\
\hline Unskilled personnel & 22 & 75.85 \\
\hline Skilled personnel & 7 & 24.13 \\
\hline Used Safe Delivery Kits (n 29) & 13 & 44.82 \\
\hline
\end{tabular}

About delivery practices, table 2 represents that more than four fifth (86.75\%) of mothers had hospital delivery. Among home deliveries just $24.13 \%$ were delivered by skilled personnel and $55.17 \%$ of mothers had used unsafe delivery kits during delivery.

Table 3: Newborn Care Practices after Delivery $(n=219)$

\begin{tabular}{|l|l|l|}
\hline Characteristics & Frequency & Percent \\
\hline Substances applied on Cord except Chlorohexadine & 124 & 58.90 \\
\hline Clean Eye of Newborn & & \\
\hline Once or more than once a day & 201 & 91.8 \\
\hline Some time & 9 & 4.1 \\
\hline Not at all & 9 & 4.1 \\
\hline Substances Applied on Eye & & \\
\hline Kajal & 188 & 85.8 \\
\hline Oil & 12 & 5.5 \\
\hline Clothes Used for Baby Wrapping & & \\
\hline New and old clean cotton clothes & 210 & 95.9 \\
\hline New and old unclean clothes & 9 & 4.1 \\
\hline Uses of Napkin & & \\
\hline Clean cotton cloth & 190 & 86.8 \\
\hline Diaper & 57 & 26 \\
\hline Ways of Making Baby Warm* & & \\
\hline Wrapping with extra clothe & 218 & 99.54 \\
\hline Keeping under sunlight & 152 & 69.4 \\
\hline Keeping warm by fire & 97 & 44.3 \\
\hline Use heater & 56 & 25.6 \\
\hline First Newborn Bath after Delivery & & \\
\hline Before 24 hours & 43 & 19.63 \\
\hline After 24 hours & 176 & 80.36 \\
\hline Oil Massage of Newborn & & 62.09 \\
\hline Two and more times per day & 136 & 32.42 \\
\hline Once a time per day & 71 & 5.47 \\
\hline Two times a week & 12 & \\
\hline
\end{tabular}


About the newborn care practice, 58.90\% mothers applied other substances except chlorohexadine on newborn cord. Similarly $91.8 \%$ of mothers cleaned the newborn eye one or more than one time a day and $85.80 \%$ regularly applied kajal on newborn eye. Majority (95.9\%) of mothers used clean new and old cotton cloths for wrapping newborn baby. Almost all mothers wrapped the baby for making warm. Very good practice found in oil massage to the newborn, $62.09 \%$ of newborn were massaged twice or more than twice in a day; likewise $19.63 \%$ provided first newborn bath before 24 hours of birth.

Table 4: Antenatal Visit of Mother and Breastfeeding Status of the Newborn $(n=219)$

\begin{tabular}{|l|l|l|}
\hline Breastfeeding Status & Frequency & Percent \\
\hline Breastfeeding & & \\
\hline Breastfeeding to the baby & 217 & 99.08 \\
\hline Not feeding at all & 2 & 0.91 \\
\hline Feeding of Colostrum & 201 & 92.20 \\
\hline Exclusive Breastfeeding to the newborn & 182 & 83.87 \\
\hline Maintain comfort for Position of Mothers and Babies & 204 & 98.88 \\
\hline Frequency of Breastfeeding ( $\mathbf{n}=\mathbf{2 1 5})$ & & \\
\hline Demand feeding & 78 & 36.27 \\
\hline 1 hourly & 75 & 34.88 \\
\hline 2 hourly & 62 & 28.83 \\
\hline Burping after feeding to the baby & 126 & 57.53 \\
\hline Status of Antenatal Visit & & \\
\hline Visit to Antenatal Clinic ( $\mathrm{n}=219)$ & 200 & 91.32 \\
\hline Frequency of ANC Visit (n $\mathbf{2 0 0}$ ) & & \\
\hline 3 times and less & 90 & 45.0 \\
\hline 4 or more & 110 & 55.00 \\
\hline
\end{tabular}

Regarding breast feeding, table 4 showed that majority (92.20\%) of mothers feed colostrum to their babies; $83.87 \%$ followed criteria of exclusive breastfeeding. Almost all (98.88\%) of the mothers maintain comfortable position of mother and baby while feeding, similarly $57.53 \%$ mothers burped their newborn immediately after breast feeding. Most $(91.32 \%)$ of the mothers had visited for antenatal checkup, however just more than half $(55.00 \%)$ had completed four recommended visit or more, which is lower than national data of Nepal.

Table 5: Level of Neonatal Care Practice among the Mothers $(n=219)$

\begin{tabular}{|l|l|l|}
\hline Neonatal Care & Frequency & Percent \\
\hline Inadequate & 110 & 50.2 \\
\hline Adequate & 109 & 49.8 \\
\hline
\end{tabular}

Concerning level of neonatal care practice; table 5 , revealed that only half $(49.8 \%)$ of the mothers had adequate level of practice and remaining half $(50.2 \%)$ had inadequate on neonatal care. Friends and relatives (94.97\%), were the most popular source of information about neonatal care, followed by health workers (31.50\%) and list (27.39\%) from mass media. 
Table 6: Association between Level of Neonatal Care Practice and Selected Socio-demographic Variables

\begin{tabular}{|c|c|c|c|}
\hline Variables & \multicolumn{2}{|c|}{ Level of Neonatal Care Practice } & \multirow[t]{2}{*}{ P-value } \\
\hline Age of mother & Inadequate & Adequate & \\
\hline$<25$ Yrs & $70(56.5 \%)$ & $54(43.5 \%)$ & \multirow{2}{*}{0.024} \\
\hline \multirow[t]{2}{*}{$\geq 25 Y r s$} & $40(42.1 \%)$ & $55(57.9 \%)$ & \\
\hline & \multicolumn{2}{|c|}{ Newborn Morbidity } & \\
\hline Age of Mother & No & Yes & \multirow{3}{*}{0.019} \\
\hline$<25$ & $57(46.0 \%)$ & $67(54.0 \%)$ & \\
\hline$\geq 25$ & $58(61.1 \%)$ & $37(38.9 \%)$ & \\
\hline \multicolumn{3}{|l|}{ Birth Order } & \multirow{3}{*}{0.001} \\
\hline$<2$ Child & $54(43.2 \%)$ & $71(56.8 \%)$ & \\
\hline \multirow[t]{2}{*}{$\geq 2$ Child } & $61(64.9 \%)$ & $33(36.1 \%)$ & \\
\hline & & Mother & \\
\hline Feeding of Colostrum & Illiterate & Literate & \\
\hline Yes & $62(87.3 \%)$ & $139(95.2 \%)$ & \multirow{3}{*}{0.038} \\
\hline No & $9(12.7 \%)$ & $7(4.8 \%)$ & \\
\hline \multicolumn{3}{|l|}{ Burping after Feeding } & \\
\hline Yes & $31(43.7 \%)$ & $95(65.5 \%)$ & \multirow{2}{*}{0.002} \\
\hline No & $40(56.3 \%)$ & $50(34.5 \%)$ & \\
\hline \multicolumn{4}{|l|}{ Antenatal Visit } \\
\hline$<4$ visit & $36(57.1 \%)$ & $54(39.4 \%)$ & \multirow{2}{*}{0.014} \\
\hline$\geq 4$ visit & $27(42.9 \%)$ & $83(60.6 \%)$ & \\
\hline \multirow{2}{*}{ Antenatal Visit } & & & \\
\hline & Not Adequate & Adequate & \multirow{3}{*}{0.000} \\
\hline$<4$ visit & $26(72.2 \%)$ & $64(39.0 \%)$ & \\
\hline$\geq 4$ visit & $10(27.8 \%)$ & $100(61.0 \%)$ & \\
\hline
\end{tabular}

Table 6, revealed that there is significant association between age of mother (p-value 0.024) and level of neonatal care practice. Similarly mother's education is associated with feeding of colostrum (P-value 0.038) and burping after feeding (p-value 0.002). There is also significant association between ages of mother (P-value 0.019) with newborn got sick. There is also significant association between income ( $p$-value 0.00) and education of mothers ( $p$-value 0.014) with antenatal checkup.

\section{Discussion}

Early marriage and child birth is common in those Muslim communities, almost all mothers (99.08\%) were homemaker among them 33.33\%were illiterate; more than four fifth (84.01\%) had planned for hospital delivery but $87.21 \%$ delivered in hospital;12.78\% were at home and 55.17\%were conducted by unskilled personnel it may be due to poor education status. A study of two different rural areas of Nepal showed $82 \%$ and $76 \%$ were of mothers had planned for 
delivery by skilled personnel [12]. Another finding from by MoHP et al. (2016), identified only 56\% of women delivered in health facilities in Nepal and another study of western Nepal reveled 91.5\% delivery had taken place at home [13]. Report of MoHP showed that 44\% home birth in Nepal [13]; likewise another study of rural Nepal found out 45.3\% home birth [14]. Similarly, in rural Bangladesh, almost all (93.7\%) had delivered by unskilled persons [6].

Concerning newborn care, $41.10 \%$ mothers applied nothing to umbilical cord which is supported by a study of rural Bangladesh, 43.9\% applied nothing on cord [6]. Almost all (99.54\%) of the mothers wrapped the baby with extra cloth, keeping under sunlight $69.4 \%$ and only $44.3 \%$ used fire to make baby warm. Opposing finding was identified in a study of Western Nepal 84.4\% had used firewood for making baby warm [13]. In this study, four fifth (80.36\%) of the women were provided first bath after 24 hours to the newborn. A study of Ethiopia also revealed $78.4 \%$ mother provided first bath after 24 hours of delivery [15]. Likewise other studies identified around half of the newborn were provided bath within 24 hours of the birth $[6,16]$.

As regards breast feeding, majority (92.20\%) of mothers feed colostrum to their babies, which is supported by others studies [14,6], which identified just $9 \%$ and 5\% women discarded colostrum prior to initiating breastfeeding respectively. In this study, more than four fifth $(83.87 \%)$ of the women followed criteria of exclusive breastfeeding, which is higher than national level of Nepal [17], it was because of almost all of the women were homemaker so that they have time for exclusive breastfeeding to their baby.

Regarding antenatal visit; most (91.32\%) of the mothers visited the clinic for antenatal checkup, but only 55\% completed $4^{\text {th }}$ ANC visit. Antenatal visit found higher than national figure $(84 \%)$ but $4^{\text {th }}$ ANC visit found lower than national figure $(69 \%)$ of Nepal [17].

About source of information almost all (94.97\%) of the mothers got information about neonatal care by friends and relatives, followed by health workers (31.50\%), however another study of rural Nepal reveled that health workers were appeared to be the most popular source for information regarding new born care [12]. In this study internet was the least used source of Information but in Bardiya, Nepal, 66\% of women used internet as source of information regarding the neonatal care [12]. Likewise, income and mother's education is associated with antenatal checkup (p-value 0.014), which is supported by a study of western rural area of Nepal [13], which revealed that there is significant association between mother's education and antenatal visits.

\section{Conclusion}

Early marriage and illiteracy found more common in those Muslim communities; around half of mothers had sufficiently practiced adequate neonatal care. Among home deliveries, more than half were delivered by unskilled personnel without using safe delivery kids. Oil massage, eye care practices and exclusive breastfeeding practice was very good, in those communities. Only around half of the women had completed fourth ANC visits and three in five of mothers applied substances except chlorohexadine in cord of newborn. Friends and relatives are the most popular source of information regarding neonatal care practice so FCHVs and health personnel should be mobilized effectively for awareness and information. Awareness campaign and mass education program on neonatal care, completions of four antenatal visit and safe delivery practice by skilled personnel are essential to enhance neonatal care practices.

\section{Compliance with ethical standards}

\section{Acknowledgments}

Researchers were thankful to University Grants Commission (UGC) for providing research grant; Institutional Review committee, IOM; the Birgunj Metropolitan city and Maharajgunj Nursing Campus, last but not the least heartfelt thanks goes to the respondents of this study.

\section{Disclosure of conflict of interest}

The authors have no conflict of interest related to research, authorship and publication of this article.

\section{Statement of ethical approval}

Ethical approval for the study was taken from Institutional Review Committee (IRC), Institute of Medicine, Tribhuvan University, then permission from Birgunj Metropolitan city office was taken before visiting the communities and 
respective wards. Informed written consent was taken with each participants with explaining the purpose and procedure of the study.

\section{Statement of informed consent}

Informed consent was obtained from all individual participants included in the study.

\section{References}

[1] UNICEF, WHO, World Bank and United Nations. Levels \& Trends in Child Mortality. 2015.

[2] WHO. Strategies toward ending preventable maternal mortality (EPMM) [Internet]. WHO. World Health Organization; [cited 2020 Jul 1].

[3] WHO. Every Newborn: an action plan to end preventable deaths [Internet]. WHO. [cited 2017 Jan 17].

[4] Government of Nepal, Ministry of Health. Nepal's Every Newborn Action Plan. 2016 [cited 2017 Feb 22].

[5] Department of Health Services (DoHS). Annual Report. Ministry of health and population: Government of Nepal. 2017.

[6] Islam MT, Islam N, Yoshimura Y, Nisha MK, Yasmin N. Newborn care practices in rural Bangladesh [Internet]. Research and Reports in Neonatology. 2015 [cited 2017 Jan 17].

[7] Khanal V, Gavidia T, Adhikari M, Mishra SR, Karkee R. Poor Thermal Care Practices among Home Births in Nepal: Further Analysis of Nepal Demographic and Health Survey 2011. PLOS ONE. 2014 Feb 28;9(2):e89950.

[8] Kayom VO, Kakuru A, Kiguli S. Newborn Care Practices among Mother-Infant Dyads in Urban Uganda. Int J Pediatr. 2015 Dec 2;e815938.

[9] Chaudhary J, Dhungana GP, Ghimire HC. Factors Affecting Newborn Care Practices Among Tharu Mothers in Selected Vilalge Development Committees of Chitwan Distract. J Chitwan Med Coll. 2013 Aug 22;3(1):42-5.

[10] Ministry of Health and Population Nepal, New ERA and ICF International Inc. Nepal Demographic and Health Survey 2011. Kathmandu, Nepal [Internet]. [cited 2019 Nov 25].

[11] Poudel D, Thapa A, Shedain PR, Poudel B. Trends and Determinants of Neonatal Mortality in Nepal: Further Analysis of the Nepal Demographic and Health Surveys, 2001-2011 [internet]. 2013

[12] A Baseline Survey on Community Based Newborn Care Package in Two Districts in Rural Nepal - Google Search [Internet]. [cited 2019 May 27].

[13] Devkota MD and Bhatta MR. Newborn Care Practices of Mothers in a Rural Community in Baitadi, Nepal. Health Prospect. 2011;10:5-9.

[14] Rezai T, Baral K, Koirala S, Paudel S, Kache S. Assessing neonatal care practices in rural Nepal. Journal of Patan Academy of Health Science, 2015 Dec 1; 2(2): 23-7.

[15] Haji Y, Teshome M, Alemayehu A, Mekonnen M, W/Gebrieal F, G/Tsasdik A. The Levels of Neonatal Care Practices at Health Facilities and Home Deliveries in Rural Sidama Zone, Southern Ethiopia. Journal of Primary Care \& Community Health. 2018; 9:2150132718812181.

[16] Kaphle HP, Yadav DK, Neupane N, Sharma B, Yadav DK, Poudel SK. Newborn Care Practices in Rural Communities of Nawalparasi District, Nepal. 2013; 3(1): 5.

[17] Ministry of Health and Population Nepal, New ERA and ICF International Inc.Nepal Demographic and Health Survey 2016. Kathmandu, Nepal [Internet]. [cited 2018 Nov 25]. 


\section{Author's short biography}

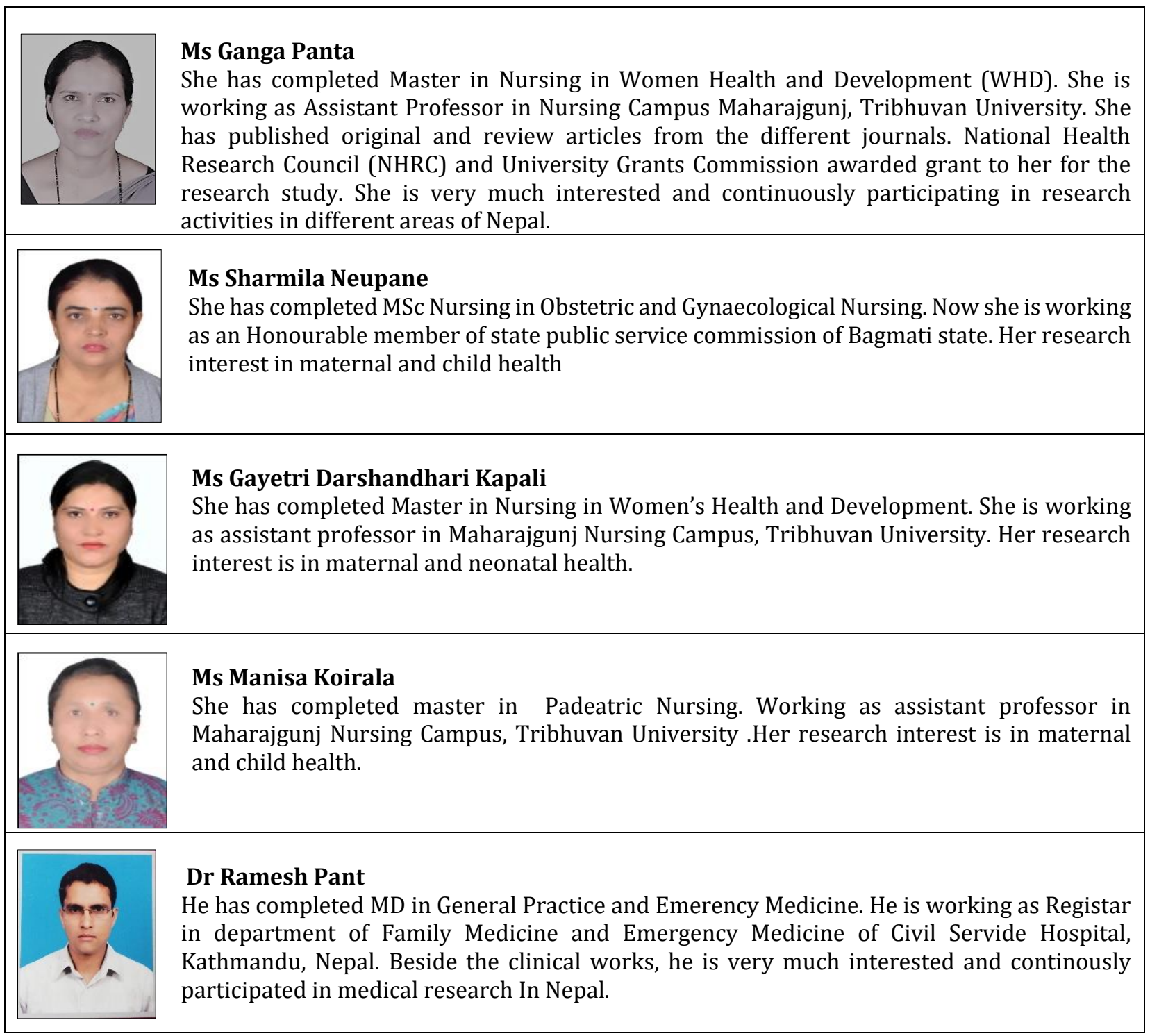

